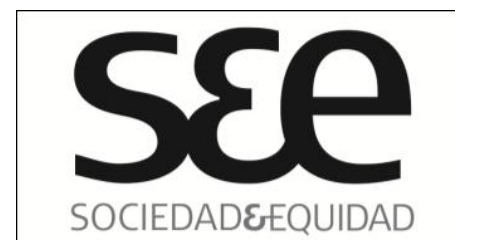

\section{Mujeres en situación de calle más allá del andar cotidiano}

Homeless Women, beyond the daily walk

$\begin{array}{ll}\text { Nombre: } & \text { Carla A. Núñez Matus }{ }^{(1)} \\ \text { Filiación: } & \text { Corporación La Caleta } \\ \text { País: } & \text { Chile } \\ \text { Correo: } & \text { nunezmatus@gmail.com }\end{array}$

\title{
Resumen
}

La realidad de las personas en situación de calle es una manifestación de la pobreza pocas veces estudiada en Chile. Realidad aún menos conocida es la que en particular vivencian las mujeres en esta condición. El presente artículo presenta un análisis de los discursos de diez mujeres entrevistadas, que se encontraban en situación de calle en dependencias de la Hospedería de Mujeres del Hogar de Cristo en Santiago de Chile, durante el año 2008. Propone, de este modo, un recorrido que matiza el concepto de situación de calle, tomando en cuenta la concepción de mujer en nuestras sociedades occidentales. Se analizan también los conceptos de pobreza, exclusión y la violencia, por estar estrechamente ligados a la experiencia de las entrevistadas. Las estructuras sociales que se vislumbran en estas historias de violencia y abandono han requerido de un enfoque de género que las problematice. Es este el principal objetivo del artículo

\section{Palabras Claves}

Personas en situación de calle, Mujer, Pobreza, Exclusión, Violencia.

\footnotetext{
${ }^{1}$ La autora es Psicóloga, Magister en Psicología Social. Sus líneas investigativas son: estudios de género, infancia y juventud desde una perspectiva de derechos y Derechos Humanos.
} 


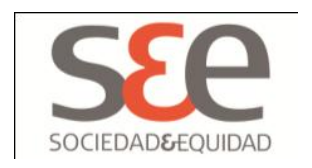

\begin{abstract}
The reality of homeless people is a manifestation of poverty rarely studied in Chile. An even less known fact is that of women living in this condition. This article presents an analyses of 10 interviews carried out in 2008 with homeless women in the premises of the Hospice of Homeless Women's "Hogar de Cristo" in Santiago de Chile. I propose a journey that clarifies de concept of homelessness taking the condition of women in western societies into consideration. The concepts of poverty, exclusion and violence are analyzed as well because they are intimately linked to the experience of these women. The social structures visible in these stories of violence and abandonment have requires a gendered perspective able to problematize them. This was the articles main objective.
\end{abstract}

\title{
Keywords
}

Homeless, Women, Poverty, Exclusion, Violence.

\section{Iniciando el recorrido}

¿Cuántas veces hemos transitado por las mismas veredas que recorren las personas que viven en situación de calle, mirando las huellas que dejan sus carros de "cachureos"* en su vaivén cotidiano? Es probable que muchas otras veces no las veamos, pues se han invisibilizado entre los escombros de la ciudad, el smog y el adoquín. Así es como ellas habitan la ciudad al atardecer; con sus colchones, sus enceres, sus historias, sin otro vehículo que sus pies. Conforman una población distinta de la pobreza, no huyen a vivir a la periferia de la ciudad, sino que por el contrario, habitan la ciudad en sus sectores más neurálgicos, en sus arterias primarias.

Pero en realidad sabemos poco de ellas. Ante la incógnita de quiénes son y cómo construyen su cotidianeidad, predomina el prejuicio y la fantasía. Estas imágenes prejuiciadas son amplificadas por los medios de comunicación masiva, los que además nos presentan personas hurañas, agresivas, tramposas, intratables,

\footnotetext{
* Según la Real Academia de la Lengua española en su $22^{\circ}$ sesión del año 2001, denomina la palabra "cachureo" como un modismo coloquial chileno, que hace alusión a un objeto inútil, y en su segunda acepción a un conjunto de objetos desechados.
} 


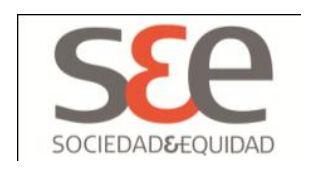

arquetipos de lo contrario al deber ser, lo que de un modo u otro moldea las imágenes que ellos mismos mantienen de sus pares. "Hay personas que se acostumbran a dar lástima. He visto viejos con fajos de billetes y piden ayuda. No se bañan. Si andan limpios no les dan comida. La miseria es una enfermedad". Patricio, 41 años, persona en situación de calle (El Mercurio, 2006: 8).

El concepto de "persona en situación de calle" ha sido construido actualmente para devolverle dignidad a quienes viven esta situación. Pues

la situación de calle puede precipitarse por un problema habitacional, pero hay otros factores que también la componen y perpetúan, como: la escasez de ingresos, la inseguridad, la estigmatización, la vulnerabilidad, la falta de elección, carencias familiares y la incapacidad de planificar (...) el significado de la situación de calle no es sólo responsabilidad de los afectados, sino que también se basa en un proceso de estigmatización social hacia este segmento de la población (Mideplan, 2005: 39).

La utilización de este nuevo concepto cobra especial relevancia si aceptamos que el lenguaje construye realidades. La idea es dotar a las personas en situación de calle de un nuevo lugar social, además de visibilizar una realidad nacional por tantos años oculta. En síntesis, se trata de comenzar a vivenciar la realidad de las personas que habitan la calle de una manera distinta. Como "persona en situación de calle" se entiende a:

(...) quien se halle pernoctando en lugares públicos o privados, sin contar con una infraestructura tal que pueda ser caracterizada como vivienda aunque la misma sea precaria; y aquellos que, por carecer de alojamiento fijo, regular y adecuado para pasar la noche, encuentran residencia nocturna, pagando o no por este servicio, en alojamientos dirigidos por entidades públicas, privadas o particulares, y que brindan albergue temporal. Asimismo, a aquellas personas que por encontrarse sin hogar o residencia, y sin apoyo de familiares u otros significativos, dependen de programas sociales que ofrecen residencia permanente o por periodos importantes, con apoyo bio-psico-social” (Mideplan, 2005: 11). 


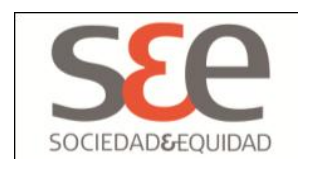

A lo largo de la historia de nuestro país, estas personas han sido objeto de distintas intervenciones por parte del Estado. El esfuerzo por alejarlas de las zonas céntricas de la ciudad, la penalización de la vagancia y mendicidad, la creación de hogares de menores, son todas iniciativas que datan de la segunda mitad del siglo $X I X$. "Aquellos individuos que sin importar su edad, su género o sus condiciones físicas, no desempeñaron oficios lícitos y viviesen de la caridad pública sin un hogar fijo, podían ser detenidos en tanto «vagos»" (Mideplan; 2005: 19).

Posteriormente, tras la penalización en el Código Civil de 1855, las materias de orden social se vieron dirigidas a la búsqueda y apoyo para la subsistencia de sectores desprotegidos de la población. Una de las primeras intervenciones, consistió en la entrega por parte del Estado de una licencia que autorizaba a las personas a mendigar, otorgada generalmente a personas discapacitadas o a mujeres que no contaban con otro medio de subsistencia. Con posterioridad, se crearon las primeras hospederías para que estas personas pudiesen pasar la noche albergadas, y despejar la vía pública. Estas fueron mayoritariamente dirigidas por la Iglesia Católica.

Tras haber observado los aires de liberación vivenciados por las mujeres europeas luego de la Revolución Francesa, a mediados del siglo XIX, las mujeres patricias de la alta aristocracia chilena encontraron en la miseria un espacio para el fortalecimiento del discurso maternal-cristiano. La mujer patricia encontró en los pobres de la calle no sólo una posibilidad de ampliación social simbólica de su familia, sino también de extensión territorial de su espacio privado y

halló en la maternidad divina de la virgen la universalidad necesaria para hacer del gobierno maternal una especie de artículo de fe... esta combinación de maternidad patricia, espacio privado, gobierno de la familia, cuestión social y maternidad divina, constituyó un cóctel ideológico estimulante y coherente, que, sin duda, contribuyó a poner en movimiento tanto el feminismo católico como el feminismo laico de las mujeres de la clase alta, como respuesta liberadora a su draconiana formación en la doctrina católica, en el código moral y en la prepotencia de su maternidad con el poder (Salazar, 2002; 130).

Así nace el culto a la "hermana de la caridad". Las mismas mujeres que por años habían vivido en torno al lujo y las historias de salón, se convertirían en las "hadas madrinas" de la miseria de los conventillos. Reunidas en pequeñas cofradías, acudían a alivianar el dolor de las madres y sus hijos abandonados en la 


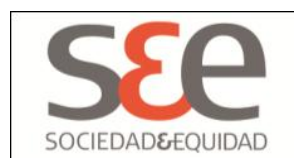

marginalidad de la miseria. Pero aquellos empobrecidos vivían de esta forma al ser marginados de la acumulación de algunos pocos, pocos que pertenecían a las familias desde las cuales salían estas mujeres piadosas.

Las políticas públicas no lograron responder a las problemáticas específicas de las personas que vivían en situación de calle, y contribuyeron en cambio a invisibilizar esta realidad social. Durante la Dictadura Militar de Augusto Pinochet (1973-1989), la cantidad de personas en situación de calle aumentó considerablemente. Hubo escasa intervención de organizaciones sociales y el Estado aminoró aún más la inversión social estatal destinada a esta población.

Con la llegada del régimen militar, se asumió como eje de la política social estatal el principio de la subsidiariedad, estableciéndose mecanismos de focalización de las prestaciones estatales, especialmente de los subsidios monetarios. Esto significó una brusca disminución de la función estatal de protección social, lo que se reflejó en una persistente caída del gasto social a partir del año 1974, especialmente en las áreas de educación, salud y vivienda, observándose al final del periodo que sólo el gasto asistencial y el previsional registraban niveles superiores a los del año 1970. (Mideplan, 2005: 29).

Las personas en situación de calle han sido excluidas durante años en Chile, desprovistas incluso de visibilidad para los chilenos. El año 2005, se realizó la primera intervención en pos del reconocimiento de las necesidades de esta población por parte del Estado. Durante el gobierno de Ricardo Lagos Escobar (2000 - 2006), se generó el catastro “Habitando la calle”, el cual constituyó un primer avance para la creación de políticas públicas que respondieran a las necesidades específicas de estos ciudadanos. Mediante dicho catastro se verificó que alrededor de 7 mil personas viven en situación de calle en Chile, de las cuales la mitad radica en Santiago (3.580 personas). El 15\% de esta población son mujeres, con una edad promedio de 44 años. Ellas indican en su mayoría que el origen de su situación de vida en la calle se debió a experiencias de abuso o maltrato, sumado al no tener casa donde llegar.

Esta población se ve enfrentada a problemáticas específicas respecto del resto de la sociedad, incluso respecto a la población en situación de pobreza. Hablamos de una pobreza intrínsecamente urbana. Así también, al interior de esta población, las experiencias que tienen hombres y mujeres varían, generando una nueva especificidad. Cada género debe responder socialmente a patrones, 


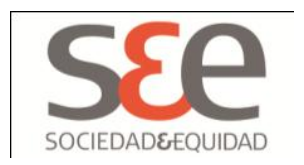

expectativas, responsabilidades distintas, manifestándose otras formas de sobrevivencia cotidiana, que son el interés de este trabajo de investigación.

Socialmente, el ser hombres o mujeres conlleva tareas, responsabilidades y visiones de mundo distintas, culturalmente aprendidas y reproducidas. Tras este supuesto se devela que la experiencia de vivir la situación de calle es distinta para mujeres que para hombres, y por lo tanto las potenciales problemáticas son diferentes.

"Mujer no se nace, se hace", decía Simone de Beauvoir (2007), y con ello ubicaba la piedra angular de los estudios feministas que a futuro intentarían rediseñar los espacios milimetrados en que se situaba la mujer. El fundamento que Beauvoir cuestionó y que años de crítica parecieran haber -en algo- socavado, es el de que los contenidos genéricos, tanto de la masculinidad como de la femineidad, responden a una "naturaleza del ser humano" que determinaría diferencias sexuales a priori, y justificaría la diferenciación de los espacios en que cada sexo ha de desarrollarse: el trabajo para el hombre, la maternidad para la mujer como íconos. Esto habría impuesto un orden eterno y por tanto incuestionable, naturalizado, que comportaría un contexto de universalidad. "Así ha ocurrido, y seguirá ocurriendo".

Lo natural se convierte entonces en universal y atemporal. Pero la categoría de mujer -y la de hombre- como contenidos intrínsecos y naturales, no pueden seguir siendo concebibles: sólo existe tal persona dentro de un juego específico de relaciones sociales con los/as otros/as, el hombre, las otras mujeres, su colectividad, el resto de grupos, la comunidad en general, la sociedad a la que pertenece. "El género no es propiedad del cuerpo ni existe originariamente en los seres humanos, sino que es el conjunto de efectos producidos en los cuerpos, en las conductas y en las orientaciones sociales” (Núñez, 2001: 82).

Desde esta perspectiva podemos suponer que cada género vivenciará de formas distintas la realidad, puesto que, culturalmente, se nos han enseñado formas distintas de presentarnos a la vida, de manejarnos en ella, de resolver los problemas, de sobrellevar la cotidianeidad. Los hombres y mujeres somos seres sociales, nos movemos en torno a normas establecidas, afectos compartidos, cooperación y también competencia.

El conocer la vida en la calle desde la particular visión de las mujeres, nos convoca a descubrir problemáticas particulares que dan un matiz distinto a esta vivencia. Para esta investigación el abordaje de las experiencias estará dado por los propios relatos de estas mujeres. Son sus voces, las que nos transportarán a sus 


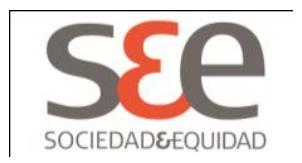

vivencias y configurarán una imagen de sus particularidades. Serán estos relatos los que nos permitirán mapear la experiencia de la vida en la calle.

Este trabajo pretende visibilizar y problematizar la particularidad de estas mujeres, pues creemos en la importancia de la re-historización de los fenómenos sociales como forma de transgresión de su ciclo de reproducción, y pretendemos desnaturalizar la problemática social a estudiar. La idea es problematizar el orden dominante y así generar elementos que permitan visibilizar otro orden en relación al fenómeno que pueda ser más justa. Es imposible pensar que problematizaremos una dominancia sin poner otra en juego. El pensar los hechos sociales como elaboraciones históricas nos permite quitarles aquellos velos de eternización que los hacen invariables e incuestionables.

Los sujetos, pasan a formar parte de posibles transformaciones de acuerdo a la movilidad de la historia social. Se abandona lo eterno, para dar lugar a las transformaciones, desnaturalizando los procesos sociales. El lenguaje cobra nueva relevancia, ya sea como constructor de realidad, mecanismo sustentador de ciertos poderes o como avalador de las posiciones desde las cuales se generan los discursos de poder.

Lo que Pujal ha nombrado "dispositivos de poder" no represivos, sino normativos, y que Bourdieu denominó Violencia Simbólica, refiere a los mecanismos que permiten que el orden establecido se reproduzca con tanta facilidad y que “(...) las condiciones de existencia más intolerables puedan aparecer tan a menudo como aceptables” (Bourdieu, 2000: 11). La dominación masculina es el ejemplo más evidente de cómo la violencia simbólica despliega su efectividad. “(...) la violencia simbólica, violencia amortiguada, insensible, e invisible para sus propias víctimas, que se ejerce esencialmente a través de los caminos puramente simbólicos de la comunicación y del conocimiento o, más exactamente, del desconocimiento" (Bourdieu, 2000: 11).

Una de las expresiones más habituales de la violencia que se ejerce sobre el género femenino es la que se da en su entorno más cercano, particularmente la que ejercen sus parejas (cónyuges, convivientes, novios, pololos), mediante malos tratos, golpes, amenazas, agresión verbal, encierro o confinamiento doméstico, abuso sexual, y en casos extremos de amenazas de muerte y homicidios. Estudios realizados por Sernam manifiestan que 7 de cada 10 mujeres sufren violencia psicológica en sus hogares de parte de su pareja, marido o conviviente, y cada año, 70 chilenas mueren producto de la violencia conyugal.

Las mujeres en situación de calle relataron que la dependencia económica las llevó muchas veces a que, luego de separadas de sus parejas o familia, no 


\section{SSe}

contaran con apoyo de otros sectores de su red social, reducida por sus labores en el mundo de lo privado.

De acuerdo a los datos arrojados por la Encuesta Casen del año 2009, un 3,7\% de la población chilena se encontraría en condición de indigencia*. Un 47,9\% de ella correspondería a hogares con jefatura femenina.

La pobreza es entendida como la privación de oportunidades a la que tenemos derecho todos los seres humanos, y por tanto, el concepto desigualdad define el acceso limitado de una población respecto de otra, a ciertos productos satisfactores de necesidades básicas, o a la escasa o nula integración en instancias de participación social, coartando las oportunidades sociales, políticas y laborales.

Se ha logrado determinar que las mujeres se empobrecerían por problemáticas distintas que las de los hombres, entre las que se derivan como más frecuentes, las relacionadas con la natalidad (madres solteras), las rupturas afectivas (abandono de familias, divorcios, viudez, encarcelamiento de sus parejas, problemas de migración), o las pérdidas de trabajo del cónyuge. En definitiva, los problemas causados por la dependencia afectivo-económica de la mujer respecto al hombre.

Son los trabajos de Hilda Scout, realizados alrededor del año 1984, los que elaboran el concepto de "feminización de la pobreza". Para ella, el sistema económico imperante generaría pauperización continua en sus habitantes. Dicha pauperización sería progresiva en el caso de las mujeres, debido a que la transferencia progresiva de la carga económica de los hijos e hijas exclusivamente hacia las mujeres, conduciría a una forma de pobreza específica, distinta y poco analizada.

Existe una disminución en el acceso a puestos de trabajo de calidad. En la actualidad, el grueso del trabajo se presenta en actividades informales, temporales (temporeras) o de servicios. Para las mujeres, el rol de cuidadoras de la salud y de responsables del trabajo doméstico, no finaliza si ellas realizan un trabajo fuera del hogar, dado que, además de las horas de trabajo, deben continuar preocupadas de la salud y educación familiar, además del aseo y la alimentación del núcleo. A este fenómeno se le ha denominado "tercera jornada". Además, como generalmente estas mujeres ejecutan trabajos de entrega de

\footnotetext{
* "La línea de indigencia urbana es de \$23.549 per cápita. Operativamente, para establecer la línea de indigencia, se sistematiza el costo de una canasta básica de alimentos por persona, cuyo contenido calórico y proteico permita satisfacer un nivel mínimo de requerimientos nutricionales y que reflejen los hábitos de consumo prevalecientes.
} 


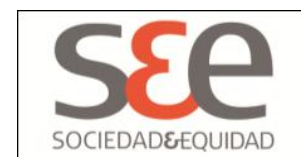

servicios terciarios para las instituciones, estas mujeres quedan fuera de cualquier tipo de previsión social, tanto para ellas como para sus familias. Tampoco disponen de ahorro para su vejez, lo que conlleva problemas sociales a largo plazo, pues sus bajas pensiones finalmente generan más pobreza en la pobreza.

Estas características propias de la pobreza femenina nos enseñan un escenario donde a las mujeres se les dificulta más el mejorar su situación. Esta hipótesis se ve corroborada por los resultados del catastro de las personas en situación de calle, que se encuentran claramente en situación de indigencia. “...El «maltrato» presenta un alto valor en las mujeres $(10,5 \%$ versus $2,5 \%$ en los hombres) y la razón «no tiene casa donde llegar» presenta también una mayor incidencia entre ellas $(21,4 \%$ versus $16,1 \%$ en la población masculina)" (Mideplan, 2005: 97).

La marcada vulnerabilidad a la que se ven expuestas las mujeres en situación de pobreza e indigencia, alcanza su cénit en las experiencias de vida en la calle. Si bien la pobreza es entendida como un concepto multidimensional, en el cual convergen múltiples variables, podemos identificar una direccionalidad común: la vía hacia la exclusión social. Entendemos como una manifestación extrema de la desigualdad social el que miembros de la sociedad queden imposibilitados de obtener por sí mismos los recursos necesarios para sobrevivir y proyectar sus planes de vida en forma autónoma y digna. El problema de la exclusión es el quebrantamiento con los vínculos sociales, lo que acarrea una pérdida del capital simbólico y material de la persona y con ello de la sociedad en su conjunto.

El modelo económico actual de acumulación capitalista promovió un modelo de crecimiento sin empleo, la contra-cara de esta fórmula fue el desempleo estructural, que convive con el "desempleo repetitivo". Este último refiere a la precaria situación de alternancia entre periodos de empleo inestable y periodos de desempleo. Así aparece la flexibilidad laboral, convirtiéndose en la nueva forma de organización. La era de la globalización presenta un nuevo escenario de crisis. La seguridad en el empleo es inexistente, en su lugar aparece la precariedad laboral y la inestabilidad, aunque todavía asociadas al viejo fundamento según el cual el trabajo remunerado es y seguirá siendo, el instrumento para no quedar en los márgenes. Así, los "marginales" se constituirán como tales, no desde la posición que ocupan, sino a partir de la relación que el sistema económico establece con ellos. La precariedad social se traduce en vulnerabilidad social. Según Robert Castel (1997), la vulnerabilidad social es el resultado de una creciente yuxtaposición entre la precariedad económica y la inestabilidad social. La imposibilidad de procurarse un lugar estable en las formas de organización de trabajo, tornan frágiles los soportes que garantizan la supervivencia individual, 


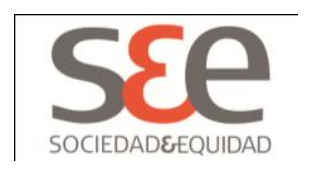

pero también debilitan los lazos de reconocimiento social que garantizan la pertenencia a una comunidad.

La mayoría de los excluidos no son explotados, o lo son en forma esporádica, por lo tanto nadie se beneficia de la exclusión social. Nadie tiene interés en ellos y no hay quien se responsabilice, culpándose sólo a la mala fortuna, el destino y la fatalidad, la falta de esfuerzo y el desgano: la exclusión social es un sujeto sin historia.

Existiría una precariedad producto de la desintegración social. No sólo hablamos entonces de necesidades económicas, sino también de necesidades del orden de la integración y participación. La exclusión no es un estado permanente, sino que construido, cambiante, y sobre todo, posible de revertir. Si pensamos en la realidad de las personas que viven en situación de calle hablamos de "[...] personas inmersas en procesos dinámicos de desvinculación -o debilitamiento gradual de los lazos- con su entorno social, que permiten, facilitan o promueven que éstas sea aisladas, rechazadas o simplemente, que se le niegue la posibilidad de participar de la sociedad y acceder a niveles de subsistencia aceptables" (Rojas, 2006: 4).

Según Beck (1996), las personas en situación de calle son sujetos institucionalizados solo por dos discursos, a la vez entrecruzados: por un lado un saber médico, que se empeña en construir su historial; por otra, un saber jurídico, empeñado en confeccionar su prontuario. Entre ambos discursos transcurre la vida de estos ciudadanos, generando miradas teñidas por la enfermedad o la delincuencia. Son este tipo de miradas las que hay que intentar opacar.

Las personas en situación de calle se caracterizan por no contar con un domicilio fijo donde llegar. Cuando hablamos de domicilio, comprendemos un lugar personal, aquel que simboliza el recogimiento cotidiano. De allí su importancia, es el lugar que reafirma nuestra presencia día a día y que sustenta nuestro estar en el mundo,

por eso si tuviera siempre que regresar como el fugitivo a otro punto de partida, y despertar en medio de objetos extraños y seres desconocidos, terminaría por perder tal vez aquellas certezas con las que cada mañana me levanto seguro de ser aquel que se acostó la noche anterior. El hecho de despertar cada mañana y encontrar la realidad circundante, allí, tal vez como la dejé, y los objetos en su mismo orden y con aquella pacífica sustentabilidad resguardadora de nuestro reposo, esto, representa un hecho 


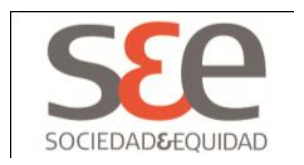

confirmatorio de que la vida no es sueño; la prueba cierta de que hay una continuidad espacio - temporal, de la que mi sueño fisiológico se descuelga cada noche y que mi sueño psíquico suele a veces perturbar profundamente. Este hecho cotidiano contribuye - digamos lo menos - a que difícilmente llegue a cuestionarme mi propia identidad (Giannini, 1997: 24).

A veces, el huir a la calle es un no domiciliarse. El tener domicilios precarios en los que no nos podemos recoger sobre nosotros mismos, es una condición de vulnerabilidad que nos hace ser no domiciliarios. No depende del techo o no techo bajo el cual nos refugiamos, sino que tiene que ver con la inexistencia de este espacio que nos permita introyectarnos, que nos de la seguridad de saber que el que duerme hoy, es el mismo que despierta mañana, que nos permite el continuar. La pobreza es tal, que no sólo atenta contra nuestros bienes materiales, sino que es una carencia que atenta contra el "sí mismo". El domicilio, es el lugar que me permite aventurarme a ir más allá, a "ganarme la vida", con la certeza cierta de que existirá una continuidad, que seguirá existiendo aquel lugar de reflexividad cotidiana. Es el lugar que nos permite la continuidad del ser, la claridad de saber que aquel que durmió ayer es el mismo que despertó hoy para continuar, nos otorga esa seguridad primaria que nos permite el devenir cotidiano.

Pero las personas que viven en situación de calle no solo sufren de la imposibilidad de la introyección dentro de su precariedad, sino que además deben lidiar con las miradas prejuiciadas del resto de los habitantes de su entorno. Inmersos en una sociedad individualista, la comunidad pasa a ser vista con ojos peligrosos, los otros ya no son iguales que pueden ayudar en caso de necesidad, solidarizar cuando se requiere ayuda, sino que predomina una mirada amenazadora en torno a los otros. Los otros pasan a ser otros siniestros y peligrosos.

La salud mental se ve fuertemente golpeada tras las experiencias de vulnerabilidad que acompañan una vida en la calle. El consumo de drogas o alcohol suele ser una herramienta para el control del estrés que significa estar constantemente en alerta cuando se vive en la vía pública. Es un bálsamo que ayuda a sobrepasar la cotidianeidad en estos espacios de continua vulnerabilidad.

El camino a habitar la calle es un proceso, no se habita un trozo de vereda de un día para otro. De a poco la calle se va configurando en el lugar de habitación, y con ello se van generando estrategias de subsistencia en este nuevo hábitat. Al principio hay temor de asentarse, se buscan distintos lugares para pasar la noche (hospederías, albergues, casas de acogida, rucos de otras personas o la misma vía pública). En algún minuto, la calle deja de convertirse en un lugar de paso, 


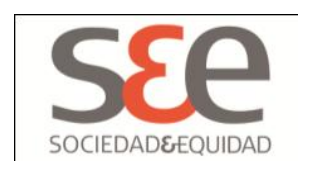

requiere asentamiento. La calle se convierte así en un lugar más o menos definitivo, un hábitat a habitar.

La construcción de los rucos es la clara manifestación de cuando la calle deja de ser un lugar de paso, para convertirse en un hogar. También se generan formas de subsistencia, se estrechan lazos con otras personas y se configuran nuevos lazos afectivos. Se aprenden las viejas estrategias de sobrevivencia que otros practican: la recolección de materiales para la posterior venta (latas, papeles, cartones, cables, fierro, mayas, etc.), sacar números en el consultorio a cambio de una propina, acarrear las verduras de la feria, hacer pequeños fletes, o pequeñas compras. De este modo, la buena relación con los vecinos domiciliados muchas veces les da otras opciones de trabajo.

\section{Ellas tienen voz}

La investigación realizó un análisis del discurso de mujeres en situación de calle hospedadas en la Hospedería de mujeres del Hogar de Cristo de la Región Metropolitana de Santiago de Chile durante el año 2008. El análisis se hizo a partir de entrevistas a dichas mujeres y no estuvo exento de complejidades, sobre todo pues nos acercamos a historias y discursos muy limitados y dolientes. "¿De qué vida quiere que le hable?, si yo no tengo vida. Nunca he tenido vida." (P. Mujer en situación de calle.)

El análisis arrojó tres grandes ejes, de los cuales se rescatan dos para este artículo. El primero es la relación con los otros actores a lo largo de sus vidas o en su situación actual, y el segundo la violencia como constante a lo largo de sus historias. Cada uno de estos ejes ha sido dividido en distintas categorías para hacer más detallado el análisis.

\section{Primer eje: Ser con otros}

El mundo de lo privado, reino histórico de la labor femenina, se ha desarrollado en torno al ser para los otros/as. Responsables del cuidado de la comunidad, el ojo está centrado en esos otros y para otros, no hacia si mismas. Su propia existencia se invisibiliza en torno a las distintas labores cotidianas que les han sido históricamente adjudicadas. Nos referimos al cuidado de los padres, las demandas de las parejas, la atención y el cuidado de los hijos/as como futuro posible. 


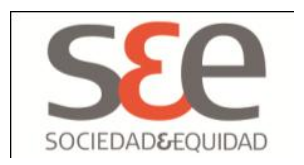

La familia es una imagen constante a lo largo de los discursos de estas mujeres. El cuestionamiento acerca de sus experiencias en la niñez junto a su familia de origen, y con posterioridad el cuestionamiento acerca de lo conseguido en sus propias familias, en la construcción forjada con una pareja y con posterioridad con sus hijos/as. Esta organización social de la familia, cimenta una especie de obligación moral, a pesar de las malas experiencias. Continuamente se expresa una idealización de este espacio como el único posible para la realización personal. La batalla a ganar como mujeres, finalmente es por cuidar este espacio propio de su responsabilidad, la familia es el campo de batalla a cuidar por ellas, es allí donde se juega batalla moral impuesta históricamente.

Sin embargo, las disfunciones en la dinámica familiar de origen suelen ser una problemática común a todas las mujeres en situación de calle entrevistadas para esta investigación. La falta de redes de apoyo, el abandono y la soledad se presentan como causales determinantes de su situación actual. Hay una autopercepción de rechazo y abandono constante, de incomprensión por parte de las personas que las acompañaban que luego se convertía en simple desinterés por sus inquietudes. "Mi familia no quiere saber nada de mí" (S).

Según el catastro realizado a personas en situación de calle, la principal razón declarada por los entrevistados para encontrarse en dicha situación fue los "problemas en la familia", un 38,2\% de los entrevistados consignaron esta respuesta. (Mideplan, 2005). En esta categoría se ubican todos quienes aseguran haber sido echados de sus hogares, o que bien por problemas al interior de sus familias, decidieron fugarse. "[...] hay veces que me sueño con esas cosas que me pasaron y despierto enrabiada y triste, la rabia con mis padres por no haber hecho nada, yo no los puedo perdonar. Eso me tiene agotada, el arrancar de esa vida, la familia la marca tanto a una. No he podido arrancar de esa rabia, de ese dolor" $(P)$.

La impotencia es una sensación manifiesta en el relato. El sentirse abandonadas, solas, sin alguien que las acompañe en el cotidiano, acompaña sus dolencias afectivas. Lo esperado es contar con adultos que velen por la seguridad de la infancia. No le correspondía a estas mujeres cuidarse, sino a esos otros/as adultos que conformaban su familia y que no cumplieron con su labor.

Podemos ver que, de este modo, se proyectan en la familia las contradicciones y crisis propias del sistema económico y social, inscribiendo el malestar público en el ámbito de lo privado. Pensar las situaciones de violencia de manera independiente de las estructuras sociales que las posibilitan, implica desconocer la complejidad de motivaciones y fuerzas que operan sobre el agresor y la agredida. Si bien entendemos al agresor como producto de un sistema de violencias, éste no queda despojado de su responsabilidad individual. 


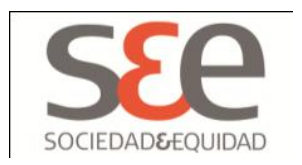

La victimización acompaña sus vidas, la impotencia por no haber hecho algo, pero también la rabia por no haber sido protegidas. La victimización es el lugar desde donde hablan de su historia, sin nadie que pudiera ayudarlas a protestar por algo que les parece injusto.

El distanciamiento y la ruptura con la familia propia, naturalizan y eternizan aquellas relaciones de violencia ya vividas en la niñez. Es aquí donde se reproduce la diferencia sexual del trabajo, coartando las libertades de cada género. Luego de las experiencias vividas en su niñez, intentan armar una nueva vida junto a parejas que prometen futuros mejores, alejándolas de los sentimientos de soledad y abandono. Sin embargo, el círculo no logra quebrarse. $Y$ muchas veces son ellas mismas las reproductoras de esas cadenas que las atrapan. “[...] yo tenía que hacer malabares para hacer comida para mis hijos, y ella se aparecía a comer también, no hacían nada. Nunca me ayudaron, nunca me dieron nada, la mamá (suegra) no hacía nada tampoco y se aprovechaban porque yo veía a los niños $(P)$ ".

La responsabilidad en el cuidado de los hijos/as está en sus hombros, cual artista de circo debe generarse cotidianamente alternativas para subsistir. La ayuda no aparece, se sienten solas nuevamente en el cumplimiento de estas obligaciones. Pero el descargo no va hacia sus parejas, quienes las han abandonado en la responsabilidad del cuidado de estos/as hijos/as comunes, sino hacia otra mujer, que por ser mujer cuenta con la misma responsabilidad social.

Las ganas de huir surgen de esa explotación cotidiana, que se suma a las otras formas de violencia que conviven en sus cuerpos y espacios psíquicos. La contradicción se vuelve notoria entre ellas, madres y amas de casa, y el hombre 'libre', autónomo, que vuelve a distintas horas cada día, que exige comida y atención. Ese hombre 'desligado', dueño de sí y dueño de ella y sus hijos. "Él era bueno para el copete. Los viernes a veces se me perdía por dos días, llegaba borracho. Nunca me preguntó si me faltaba algo a mí o algo para los niños” $(P)$.

Los hombres cuentan con libertades. Ellas están al cuidado de los/as hijos/as y deben hacerse cargo de su labor naturalizada. Los hombres salen, disfrutan, son despreocupados; las mujeres que buscan atención, siguen sin ser escuchadas, sin ser percibidas, invisibilizadas en su quehacer doméstico.

Constantemente está presente el imaginario de volver, volver a la familia que las expulsó. Con relación a los lazos familiares, el catastro demuestra que en promedio, el último contacto entre algún familiar y la persona en situación de calle ocurrió hace 3,3 años en relación a la fecha de la encuesta. Pero se observan diferencias en la desagregación por género: los hombres presentan un valor 


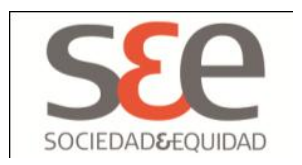

promedio de 3,5 años desde su último contacto familiar, frente a 1,8 en las mujeres.

Continuando con los datos entregados por el catastro, podemos dar cuenta que el restablecimiento de los vínculos familiares es explicado por diversas causas según las personas encuestadas, de las cuales destacan: necesitar ver o compartir con familiares e hijos $(40,1 \%)$, ser contactado o visitado por la familia $(12,8 \%)$, requerir dinero o alimentos $(8,5 \%)$, visitar familiar enfermo o a la familia en caso de un fallecimiento $(6,6 \%)$, informar sobre cómo y dónde está $(5,8 \%)$.

Por otra parte, el Informe Voz y Ciudadanía (2005), señala como demandas asociadas a la categoría de Integración Familiar: la necesidad de contar con mayor información sobre redes de apoyo familiar, la generación de estrategias para atraer a las familias a estos servicios, (con el fin de fomentar la demanda de beneficios), la creación de un centro de orientación y apoyo familiar y sobre todo fomentar el buen trato en la familia.

Las señales son claras: el rediseño de los vínculos afectivos es prioritario, y las mujeres entrevistadas no están aisladas de esta imperiosa necesidad. "Echo de menos a mi papá. Bueno, también quiero a mis hermanas, no las critico ni las condeno porque no soy nadie para condenar. Igual las quiero, las adoro, y ya vendrá el momento en que podamos conversar... (M).

Tal como lo reconoce el Informe de Resultados de Asambleas Regionales Voz y Ciudadanía (RedCalle, 2005), es necesario acceder a una "mediación familiar" que permita reforzar el amor y apoyo incondicional dentro de un clima no violento, de tolerancia y respeto (Voz y ciudadanía 2005).

Se espera con ansias el minuto del reencuentro, el minuto en donde las aristas y las relaciones quebradas logren confluir, logren conversar. Hay una sensación como que todo es solucionable, solo hay que esperar el minuto oportuno, cuando las heridas cierren. Hay cosas que negociar, resolver. Sin embargo ellas esperan volver en una nueva posición, una posición que las haga florecer, otros no pueden verlas en la situación en que están ahora, tocando fondo, cansadas, perdidas. No, tras salir del infierno en el que ahora se encuentran se renovarán las oportunidades y una ilusión de florecimiento y maravillas las embriagará, volverán como pares, dueñas de sí mismas. Con herramientas que les permitan pararse frente a un igual, no quieren que las vean como están. Pero ¿cómo están? Solas, cansadas. No quieren que el reencuentro se presente en este escenario. Quieren que las vean mejor, ¿y qué es en realidad este mejor?, verse mejor se asemeja a estar mejor, el tener mejores ropas, estar limpia, con posibilidades de tomar decisiones en libertad, dueñas de sí misma, a la moda. 


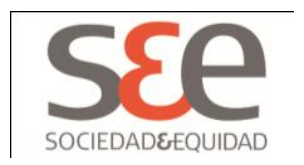

La situación de calle es concebida siempre como un tránsito, un proceso dentro de sus vidas que se resolverá en el futuro inmediato, como un problema puntual más que como una situación compleja en su globalidad. "Me complica solucionar el problema" (R), pudiendo recobrar las vidas interrumpidas.

Muchas veces existe una idealización del lugar a recobrar. La construcción de esos nuevos espacios sin viejas reproducciones, con nuevas conductas, más armoniosas y saludables. El estar al margen, provoca una idealización de los incluidos, aquella otra que trabaja, que se hace cargo de sus hijos, es mejor, su vida no tiene problemas, roza la perfección. Ellas han jugado mal las cartas y deben regresar a hacer bien las cosas. Aquella mujer que logra todo es su imagen idealizada, ella les hace sombra.

La relación con sus parejas está siempre presente en sus diálogos. La violencia no deja de ser una constante a lo largo de las vidas de estas mujeres, quienes luego de salir de sus hogares de origen, comenzaron a establecer sus propias familias. Es claro sin embargo que sus historias no lograron romper con la estructura que moldea las conductas, tanto de ellas como de sus parejas. Y al final siempre es lo mismo.

"Puesto que la familia coercitiva, desde el punto de vista económico e ideológico es parte constitutiva de la sociedad autoritaria, sería de ingenuos esperar la desaparición de sus estragos en el marco de esta sociedad. Además, no se olvide que estos estragos son inherentes a la constitución misma de la familia y están fuertemente anclados en cada individuo gracias a mecanismos inconscientes" (Reich, 1993).

Si bien no es de interés para esta investigación realizar descripciones que caractericen a los hombres, -a las parejas de las mujeres entrevistadas-, sí es necesario encontrar esos puntos comunes en cada uno de sus relatos. Hablan de un pasado idealizado cuando recuerdan a sus parejas, todo estuvo en un aura de encantamiento, no había problemas y todo parecía que tomaba rumbos nuevos, donde el cariño, el enamoramiento, marcaban la pauta de algún futuro en construcción mucho mejor que el pasado que se dejaba. Y es que acaso, ¿quién al comienzo de una relación, no siente que la fantasía y el encantamiento cobran nueva vida, posibilitando futuros mejores? La ilusión se apodera de nuestra realidad, nos emboba. "[...] me empezó a conquistar, me llevaba flores, a mí me aburría, yo no quería nada con él, y ahí después me empezó a conquistar, yo le tiraba agua para que se fuera" $(R)$.

El juego de la conquista fue un aire en sus vidas. Buscadas, mimadas, dejaron de ser invisibles para comenzar a ser deseadas por alguien. El espejismo se 


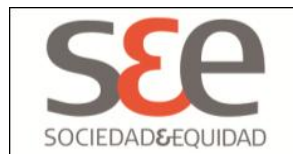

constituye como tal, convence, ambos realizando esfuerzos por verse, por compartir, por disfrutar la aparente suspensión de las diferencias sexuales, permitiendo por única vez el reconocimiento de la mujer y una valoración de sí en cuanto persona individual e incambiable por sus cualidades singulares.

Pero un quiebre aparece y rompe la ilusión, la violencia explícita se hace presente. Las entrevistadas intentan señalar una génesis, un punto original desde el cual comenzó la agresión, las amenazas, el miedo. Punto destacado y diferenciado de ese "antes" armónico. "[...] antes era más tranquilo; tomaba de vez en cuando. Todos los años nos íbamos con toda la maquinaria pa' donde fuera, donde se nos pararan los pies y trabajábamos, veraneábamos y trabajábamos. Hacíamos el pan, vendíamos y nos iba súper bien... nos íbamos de enero a marzo, a veces, tomábamos la Semana Santa y lo pasábamos bien." (R)

Los Hijos, rompen el estado de libertad, vienen a sembrar un ancla y los problemas comienzan a aparecer. Las responsabilidades son cohartadas. Hay una intención por justificar las situaciones de agresión, la factura se la llevan los hijos, tras ellos las cosas cambian, la maternidad requiere de sacrificios. Las cosas habrían cambiado, de pronto un suceso hace que la ilusión se rompa. Antes las cosas eran armónicas, tranquilas, un evento repentino hace que las cosas cambien, que todo pierda rumbo, que los golpes aparezcan, que el abandono se repita.

La lectura que ellas realizan de su historia es progresiva, hay un deseo y una percepción que a pesar de lo vivido, cada vez estaré mejor. Actualmente hay un quiebre, pero es por un tiempo, ya vendrá el florecer. Con esfuerzo sienten que pueden cambiar las cosas, es cosa de mancharse un poco con el discurso emprendedor. Está en mis manos, requiere tan solo de mi esfuerzo.

De acuerdo a los resultados del Catastro realizado a personas en situación de calle, sólo un $12,6 \%$ de las mujeres en dicha condición vive con sus hijos/as (porcentaje que en hombres corresponde a menos del 1\%). La maternidad se vive en soledad, los hijos son responsabilidad de ellas, pues siempre ha sido así, las madres se quedan con los pequeños, aún cuando el padre ha decidido abandonar. Lo tendré sola, sola he estado siempre y así continuaré, siempre ha sido igual. (C)

Los hijos/as vienen a reafirmar esa sensación de soledad, frente a la adversidad no hay compañía que ayude a resolver los conflictos. Los hijos /as son una extensión de ellas mismas, no alcanzan a convertirse en otro. La preocupación por los hijos/as no pierde su centro para quienes los han dejado al cuidado de sus familiares o en internados, y toma una fuerza que mueve, que llena de sentido, el deseo de reconstruir una vida junto a ellos/as. Es en esta soledad donde se deben buscar nuevas motivaciones, nuevos significados para continuar viviendo desde las 


\section{SEe}

decepciones acumuladas. "Por los hijos hay que luchar (...) los hijos a uno le dan razones (...)" (M)

El ser madre entrega un lugar, una identidad, su invisibilización toma un respiro, comienzan a ser miradas desde su ser madres. Si se sacrifican lo suficiente alguien podrá entregarles la calidad de "buenas madres" que es una ganancia importante.

Un nuevo problema emergente, la red de apoyo que recibe a los hijos/as para cuidarlos, para custodiarlos mientras la madre resuelve su entramado de quebrantos y dificultades, cuestiona y recrimina, se opone y amenaza, manipulando lo poco que queda... el sueño de reencontrarse. El ser madre incluye esa posibilidad; ser cuestionada -y quienes rodeamos no dejamos de hacer uso de ella-, criticada por las formas y elecciones. Si hacen mal su trabajo, la ganancia continua, los ojos están puestos en ellas, son visibilizadas.

Nadie logra entenderlos ni amarlos tanto como ellas, el compromiso es a perpetuidad, ellas son lo mejor que cada uno de esos pequeños puede tener, porque es ley de vida, la madre ama a sus hijos, porque así debe ser, porque eso es lo que nos han enseñado, sus vidas como mujeres, parejas o trabajadoras pueden haber fracasado, pero no el ser madres, esa es una batalla que no se puede perder... al menos, no otra vez. "Mi mamá también vivió en la calle, por eso nosotros fuimos criados en distintas partes, y es eso el que a mí me hace querer cambiar, cambiar las cosas, no que mi hijo viva como mis hermanos [...]" (C.)

Siempre es otro el que les permite vivir: o son sus parejas, o son sus hijos/as. La imposibilidad de mirarse en la individualidad hace que constantemente sea a través de estos otros/as.

\section{Segundo eje: Violencia}

La violencia y sus distintas manifestaciones son dinámicas que se traslucen continuamente en los relatos de estas mujeres, violencia de hoy, violencia de ayer, sus historias han tenido un matiz continuo de agresiones.

Es la división sexual del trabajo la manifestación más tosca de esta violencia, aquellas formas naturalizadas de entender las responsabilidades, concibiéndolas como propias y erradicables. Los cuerpos se adaptan, los deseos también. $Y$ es de esta división y su naturalización que estos relatos también dan cuenta. "El sistema que programa la computadora, que alarma al banquero, que alerta al embajador, que cena con el general, que emplaza al presidente, que intima al ministro, que amenaza al director general, que humilla al gerente, que 


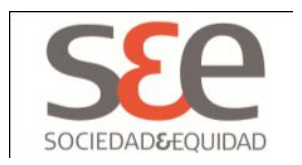

grita al jefe, que prepotea al empleado, que desprecia al obrero, que maltrata a la mujer, que golpea al hijo, que patea al perro" (Galeano, 1997; 45).

Y a través de la naturalización de estas formas de relacionarnos, la violencia cala nuestras relaciones sociales, en todo ámbito. Invisible a nuestro actuar, reproducimos y provocamos nuevos escenarios para que haga su aparición. Estos relatos que históricamente han estado teñidos por manifestaciones incluso más visibles de esta violencia, son los que revisaremos en este eje.

El catastro a personas en situación de calle (Mideplan, 2005), presenta como razones o motivos para haber llegado a la situación de calle los problemas con la familia (38,2\%, conformándose en la principal) y el abuso y maltrato (que en total ascienden al $35 \%$ de las razones dadas por los entrevistados/as). Los problemas al interior del núcleo familiar muchas veces producen que la calle se vuelva un escenario posible e incluso atractivo para vivir, o bien para buscar alternativas que permitan salir de estas situaciones.

La violencia cobra matices históricos distintos, la posibilidad de la denuncia, la problematización en cierta medida de los roles con el ingreso de las mujeres al trabajo no ha dejado a estas mujeres ajenas. En la medida en que podemos entender los géneros como inseparables uno del otro, formando un sistema histórico de relaciones que se constituyen y modifican en sociedad, podemos dimensionar los efectos que las transformaciones en la asignación de los roles, (el acceso a la educación, el trabajo, etcétera) han significado cambios en la constitución de la masculinidad.

“(...) muchas veces se ve en la televisión lo que uno tiene que hacer, que las mujeres no tienen que dejarse agredir, que ya basta con la violencia intrafamiliar, tanto con los niños como con la mujer, porque la que se queda y aguanta es una tonta, porque hay muchas mujeres que han muerto por los mismos maridos, que les han pegado, las han maltratado, y después se arrancan" $(R)$.

La información y las campañas también llegan a ellas, la percepción de que aguantar ya no es obligación sino que quien aguanta los malos tratos de su pareja se convierte en una tonta es un fuerte llamado de atención a sus vidas y experiencias. Hay que arrancar, sino es la propia vida la que se pone en juego. Pero la problemática es mucho mayor, las decisiones no se toman de un día para otro, y ya suficiente se ha vivido a lo largo de la historia, como para saber que se puede aguantar siempre un poco más.

No son solo los golpes, sino que es la duda, los celos, los malos tratos, la falsa calumnia, la privación de mantener relaciones de amistad con otras personas, 


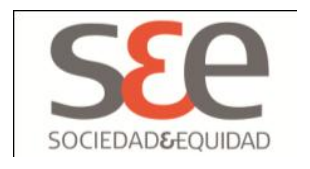

la duda que encarcela, que anula, que desconfía y las deja cada vez más solas en un espacio delimitado por ese agresor.

Pues la agresión se esconde tras esta desconfianza perpetua, siempre pueden ser culpables de algo, aun cuando no quieran, aun cuando no se den cuenta, la mujer es propiedad, y debe hacer lo que el dueño desea. "(Mis hermanas dijeron) [...] que yo me metía con cualquier tipo, que si me hubiese cuidado..." (M).

La impotencia hace su aparición otra vez, ahora debido a la desconfianza que la pone en juego frente a otras personas. Es la calumnia que sobrepasa los espacios, que permite que otros actores también desprecien, también cuestionen el actuar de estas mujeres, quienes poco a poco se sienten imposibilitadas de responder a esas acusaciones. Se minan las percepciones que las mujeres tienen de sí mismas, reforzando con ello la positividad de la masculinidad. Los padres, las hermanas, los vecinos, también cumplen un rol en la tarea represiva.

Hay una necesidad continua de corroborar que esas calumnias no son verdaderas, que esas mentiras no han podido llegar a desprestigiarlas en todos los espacios. La duda ha minado incluso sus propias certezas. "Me dice que soy esquizofrénica... si yo fuera una persona esquizofrénica, yo no estaría conversando aquí con usted ni con la gente, y no hubiese entrado a trabajar al supermercado porque ahí también nos hacen entrevistas con psicólogos, nos hacen los test y gracias a Dios me salió bien" $(R)$.

"Lo que partió con esas palabras que soltaba, hirientes y dolorosas, paulatinamente devino en seguimientos, amenazas. Los golpes. Después fue simple llegar a los golpes. [...] varias veces me golpeó, varias veces le dije que por favor se tranquilizara, que por favor, que reaccionara, que por los niños, que cambiara, pero no cambió" $(R)$.

Los golpes hacen su ingreso, ya no hay nada que conversar, no hay comunicación posible, solo es la agresión. A pesar de intentar que estos golpes se acallen por los otros, ni siquiera ya por ellas mismas, sino que por los hijos/as, para evitar el ejemplo, por ese futuro posible las cosas podrían cambiar, sin embargo no cambian. [...] mi pareja me contagió con el VIH, quedé embarazada [...] cuando supo, él se fue (M).

Y el poder que es ejercido sobre los cuerpos de las mujeres no consigue acallar la exigencia masculina de la virilidad, se sofistica y se lanza a un desafío mayor. Poseer la vida toda y su destino. 


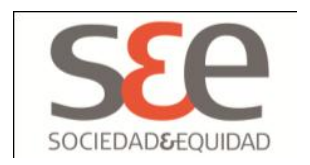

Pero la violencia no solo se vivencia en los espacios familiares, la violencia se siente en todas partes, como si se fuera junto a su sombra, aparece en los distintos lugares donde han decidido marchar buscando solución. En la calle, en la hospedería, la violencia continúa. "No tenía otra opción, no quería venir para acá (a la hospedería), no lo pasé bien la primera vez [...]" (S). Pero no hay donde elegir, las opciones son escasas, aquí no lo paso bien, allá tampoco, ¿Dónde partir? "Yo acá no soy conflictiva, es que llega de todo un poco, entre que le roben a uno, entre que..." (S).

Y en todos los espacios siguen sintiéndose vulneradas, como si el sino de la victimización no pudiera quebrarse. En todas partes se respira el conflicto, los problemas, la agresión. Aun cuando uno no quiera participar, aun cuando uno sea tranquila y no moleste.

Dan ganas de irse, se añora lo "propio", y el cansancio de vivir alerta todo el tiempo, de no poder soltar el control sobre las pertenencias. El control es lo que cansa, controlar y ser controlada. “(...) por la gente, por todo no sé. Por la gente que viene aquí... Me quiero ir, lo antes posible. Con nadie he peleado, nunca he tenido problemas con nadie, pero he estado mal porque hay que pedir permiso hay que avisar a qué hora uno llega a qué hora uno sale..." (S).

Hay un control sobre sus vidas, un control que no desean. Ese control no está en la calle. La calle es más libre, aunque esté más llena de privaciones. Y es esa la decisión que día a día las confronta, la calle y sus privaciones les permite a ellas ciertas libertades, la sopa caliente de la hospedería se paga, se paga con libertad. El control se siente opresor. "No le doy a nadie el vivir en la calle, uno sufre mucho, duele mucho..."(C).

La calle y sus violencias. La gente desprecia, se pasa hambre. La mugre, te llenas de mugre hasta camuflarte. Y eres basura, ante los ojos de los demás, no eres distinto de cualquier desecho, y eso es humillante, ¿acaso vuelve la invisibilidad de la cual querían escapar?, vuelve, y ahora son más los que humillan con sus ojos lastimeros, con sus miradas hirientes.

Es claro que en cotidianidades como estas, los niños no escapan a la atmósfera que todo lo invade. Los niños pelean entre ellos, se golpean... y contestan mal, con las groserías que tantas veces les han dirigido a ellos mismos. “(...) que antes donde yo estaba, a mi hijo antes le pegaban (...) le pegaban con palos, con fierros, con maderas... “(C).

Y la hora es perentoria en su mandato, hay que irse, la hospedería es siempre transitoria. Las mujeres quieren irse, pero siempre es difícil vislumbrar un espacio. Aparecen los sueños, es cierto, pero la realidad es distinta, se hace de otros materiales. Ya ven, ahí están las experiencias anteriores, todo tiene su costo, todo se paga. Mejor no respirar. Si molestas, te vas. “(...) mi patrón me 


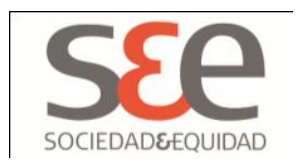

dejaba dormir donde guardan las camionetas, el tenía una panadería y yo todas las mañanas tenía pancito calentito, tecito, cualquier cosita pa'l pan y me daba cosas... Él se enojaba con la señora y se desquitaba conmigo así es que eso..." (C).

La hospedería es transitoria, en una vida llena de tránsitos ¿Cómo es que se elabora este saber, el de que todo seguirá igual? Porque eso es lo que pasa, que no se ven posibilidades de cambiar la vida previa a la hospedería. De alguna manera, tras los sueños de una vida propia, se vislumbra la certeza que alimenta el cansancio, que pesa hasta la rendición. “(...) tengo 43, a veces siento que es imposible y que las cosas van a seguir pasando" $(P)$.

La impotencia juega otra vez junto a ellas, ¿será posible un espacio distinto?, el cansancio aparece, el cansancio tras haberlo intentado otras veces y sin embargo recibir solo nuevas frustraciones.

\section{Conclusiones}

Considero relevante comprender que las mujeres que viven en esta situación en general han vivido y continúan viviendo relaciones manchadas de violencias. Muchas veces las acompañó en su niñez la violencia explícita por parte de sus padres o familia de origen, el abandono de los suyos. La falta de herramientas que imposibilitaron la resolución de conflictos al interior de la familia, el maltrato, el abuso sexual, la precariedad, significaron en muchos casos los primeros escenarios que dibujaron la calle como lugar de escape de las violencias cotidianas, debido a la inexistencia de otras posibilidades.

Sin embargo, es importante considerar que cada una de las problemáticas surgidas al interior de estas familias se inscribe en un proceso mayor de violencia. Hay dolor en ellas, rabia y frustración inmensa de saber perdida la baraja de la vida. La infancia trisada por la violencia sexual, el maltrato físico y la serie sucesiva de violencias producidas y reproducidas al interior del núcleo familiar perduran en la adultez y volverán a aparecer en sus relaciones con otros/as.

Pertenecer 'por naturaleza' a la familia, significa renunciar a sí mismas, aceptar la dependencia implicada en el 'vivir por los demás'. La mujer al servicio del hogar se fue constituyendo a modo de cortapisa entre lo privado y lo público, en la medida en que como administradora de los bienes simbólicos resguarda en el ámbito de lo privado aquellos valores subvertidos en el ámbito de lo público, (entiéndase, altruismo, comunidad, etc). Llegados los hijos la labor aumentó. Una nueva responsabilidad aparecía en sus vidas, y muchas veces esta responsabilidad 


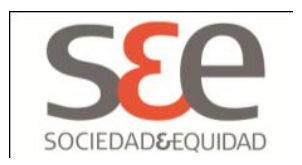

fue solo de ellas: madres solteras con compañeros ausentes, convierten a sus hijos en la razón para imaginar futuros posibles. Movimiento fundacional en el devenir del ser madre en nuestro continente: ser madre sola, ser hija huacha.

El círculo de la vida se acorta, se contrae en un movimiento silencioso, imperceptible. El ser mujer, con todos sus sentidos fijos y también titubeantes comienza su camino -con o sin retorno- hacia la cumbre virginal de la sublimación. Ser madre es la transfiguración sacrificial del ser mujer.

La violencia es otro común denominador a estas historias de mujeres en situación de calle. Ella se inmiscuye en los espacios, y finalmente es la forma que conocen de relacionarse y expresar emociones, la soledad no les ha dejado más enseñanzas.

La violencia va mucho más allá de la visibilización, no depende exclusivamente de la introyección del consabido discurso de derechos y procedimientos, sino más bien de una problematización integral de los variados factores que convergen en la conformación relacional de las identidades genéricas, y que constituyen los soportes que facilitan y posibilitan las estructuras de dominio que caracterizan nuestro sistema cultural patriarcal. En este actual modelo de desarrollo se hace prioritario mirar y repensar la crisis de la masculinidad desde la cual brotan los agresores con sus justificaciones, intentado mensurar los costos que el orden establecido provoca también en ellos.

Dichas prácticas desde luego que están presentes en los relatos de las mujeres en situación de calle y ocupan un lugar nada inocente respecto de su actual situación. Si bien la violencia de la que han sido víctimas es en general proveniente de sus parejas, ésta no está ajena a otra serie de violencias que vivimos en el cotidiano, por lo cual podría entenderse como otro producto de un sistema estructural que las posibilita y requiere.

¿Cómo no considerar violenta la fuerza que empuja irremediablemente a miles de vidas a determinadas realidades de marginalidad? ¿Cómo aislarla de las situaciones que desencadenan tal o cual arbitraria determinación? 


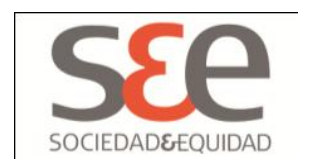

\section{Referencias Bibliográficas}

Arriagada, I. (2005). Dimensiones de la pobreza y políticas desde una perspectiva de género. Revista de la CEPAL N 85, Abril 2005: 101-113.

Bauman, Z. (2005). Trabajo, consumismo y nuevos pobres. Barcelona, España: Editorial Gedisa.

Beck, U. (1996). Teoría de la modernización reflexiva. En Beriain, J. Las consecuencias perversas de la modernidad. Barcelona, España: Anthropos.

Bourdieu, P. (1999). La miseria del mundo. Buenos Aires, Argentina: Fondo de la cultura económica.

Bourdieu, P. (2000). La Dominación masculina. Barcelona: Editorial Anagrama.

CASEN (2009). Encuesta de caracterización socioeconómica nacional. Mideplan. Chile.

Castel, R. (1997). La metamorfosis de la cuestión social. Una crónica del asalariado. Buenos Aires, Argentina: Piados.

De Beavoir, S. (2007) El segundo sexo. Barcelona: Editorial De Bolsillo.

El Mercurio (2 de Abril 2006) Ruta de la cuchara. Cuerpo C. Nacional. Pagina 8. Santiago de Chile.

Galeano, E. (1997). Apuntes para fin de siglo. Santiago de Chile: LOM.

Giannini, H. (1999). La reflexión cotidiana. Hacia una arqueología de la experiencia. Santiago de Chile: Editorial Universitaria, Colección el saber y la cultura.

Ministerio de desarrollo y planificación social. (2005). Habitando la Calle. Catastro nacional de personas en situación de calle. Ministerio de Planificación. Gobierno de Chile.

Núñez, L. y Souza, C. (2001). Construcción social de la maternidad en la práctica discursiva de los(as) sujetos(as) lesbianas. Tesis para optar al grado de Psicólogo. No publicada. Universidad ARCIS. Santiago de Chile.

Pujal (1991). En Núñez, L. y Souza, C. (2001). Construcción social de la maternidad en la práctica discursiva de los(as) sujetos(as) lesbianas. Tesis para optar al grado de Psicólogo. No publicada. Santiago de Chile: Universidad ARCIS. 


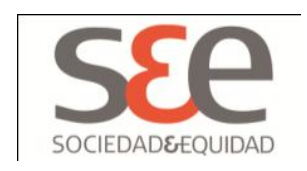

Rojas Pedemonte, N. (2006). Personas en situación de calle en la perspectiva de la exclusión y la vulnerabilidad social. Aproximaciones a la construcción de un marco comprensivo. En Reflexiones acerca de las personas en situación de calle. (2006). Santiago de Chile, Chile. Formato electrónico en http: / / www.redcalle.cl/descripdecla.asp?ImagelD=299

Salazar, G. y Pinto, J. (2002). Historia contemporánea de Chile, Tomo IV. Hombría y feminidad. Santiago de Chile: LOM

Riech, W. (1993). La revolución sexual. Barcelona: Editorial Planeta-Agostini.

RedCalle y otros (2005). Voz y Ciudadanía para las personas en situación de calle. Informe de resultados asambleas regionales. 